EXTENDED REPORT

\title{
Radiological outcome after four years of early versus delayed treatment strategy in patients with recent onset rheumatoid arthritis
}

\author{
J van Aken, L R Lard, S le Cessie, J M W Hazes, F C Breedveld, T W J Huizinga
}

Ann Rheum Dis 2004;63:274-279. doi: 10.1136/ard.2003.010298

See end of article for authors' affiliations

Correspondence to:

Correspondence to:
Dr J van Aken, Department of Rheumatology, Leiden University Medical Centre, PO Box 9600, 2300 RC, Leiden, The Netherlands; j.van_aken@lumc.nl

Accepted 30 June 2003

\begin{abstract}
Objective: To determine the effect of different treatment strategies (early versus delayed) on the radiological progression of joint damage during 4 years. Additionally, to determine the effect of treatment strategy on the association of HLA class II alleles and joint damage.

Methods: Progression of radiographic damage and association of radiographic damage and genetic predisposition were compared in two cohorts, one treated according to the delayed treatment strategy (initial treatment with analgesics), the other treated according to the early treatment strategy (treatment with disease modifying antirheumatic drugs (DMARDs) chloroquine or sulfasalazine). Radiographic damage was measured by the modified Sharp-van der Heijde method. Genetic predisposition was determined by high resolution HLA-DR and DQ typing.

Results: A completers-only analysis of 153 patients (originally 206 patients) in a non-randomised design showed less radiographic progression from 0 to 4 years in the early treatment group (median Sharp progression rate 1.3 points/year, $n=75$ ) than in the delayed treatment group ( 2.5 points/year, $n=78$ ) $(p=0.03)$. The progression from 1 to 4 years did not differ significantly between the groups. At 4 years, joint destruction in both groups was positively correlated with the presence of the shared epitope.

Conclusions: The beneficial effect of early DMARD treatment on the radiological progression of joint damage is still present at 4 years. However, the rate of joint destruction from 1 to 4 years did not differ between the delayed and early treatment group. Neither the radiographic nor the immunogenetic data suggest that longlasting disease modification has been induced by early treatment.
\end{abstract}

$\mathrm{R}$ heumatoid arthritis (RA) is a chronic autoimmune disease with a variable course and outcome, which may result in progressive joint destruction and physical disability. ${ }^{1-3}$ To reduce joint inflammation, joint destruction and, thereby, disability, disease modifying antirheumatic drugs (DMARDs) are prescribed. However, in most patients with established RA, the benefits of DMARD treatment are insufficient. ${ }^{4-6}$ A so-called "window of opportunity" theory was proposed, in which institution of DMARDs at an early stage of the disease would have a dual effect. A short term effect would reduce clinical disease activity and a long term effect would modify the disease to a milder course. This theory is analogous with other disease states, where detrimental characteristics are acquired during the course of the disease. Examples can be found in oncology, where tumour cells spread from the original tumour to the regional lymph nodes and eventually disseminate to metastatic disease. The curative effect of a surgical or chemotherapeutic intervention depends heavily on the stage at which the disease was first treated. In RA, it is unknown if and when such detrimental characteristics are acquired during the course of the disease, although sequential events that take place in patients who develop RA have been suggested. ${ }^{7}$ The proposal of this "window of opportunity" was indirectly supported by a number of trials and analyses that have studied early institution of DMARDs in patients with early disease. ${ }^{8-11}$ These studies demonstrated that early treatment with DMARDs effectively controls disease and/or reduces radiological progression in RA with median disease duration of $<2$ years with or without baseline joint damage. However, whether the observed beneficial effects of early treatment are temporary or long lasting remains to be determined. A study that examined this issue is the 5 year follow up of a placebo controlled study in which early treatment with auranofin was compared with a delayed treatment strategy. The results of this trial demonstrated improvement in the early treatment group for clinical variables, functional outcome measures, and radiographic progression, supporting the existence of a therapeutic "window" within the first two years of the disease. However, the reported number of 75 patients (35 patients in the delayed versus 40 in the early treatment strategy) was relatively small. ${ }^{12}$ In a 6 year prospective cohort study, comparable favourable results were suggested with early treatment, mainly with sodium aurothiomalate during the first year, based upon the comparison of early treatment with historical controls. ${ }^{13}$

Apart from radiographic outcome studies, immunogenetic studies have been performed to explore mechanisms of disease modification. In established RA, progression of joint damage is associated with HLA class II alleles. ${ }^{14-17}$ Recently, we demonstrated that early and aggressive treatment of very early RA (median disease duration 4 months) abolishes the association of HLA class II alleles with progression of joint damage, during the first 2 years of the disease. ${ }^{18}$ This effect was demonstrated for both the comparison of early versus delayed treatment and for the comparison of combination therapy including prednisolone, methotrexate, and sulfasalazine versus sulfasalazine monotherapy. ${ }^{19}$ Thus, it could be

Abbreviations: ACR, American College of Rheumatology; DMARDs, disease modifying antirheumatic drugs; EAC, early arthritis clinic; ESR, erythrocyte sedimentation rate; NSAIDs, non-steroidal anti-inflammatory drugs; RA, rheumatoid arthritis; RF, rheumatoid factor; $S E$, shared epitope 
proposed that, next to the rate of joint destruction, the association of HLA class II alleles with progression of joint damage can be used to assess whether disease modification has occurred by early treatment. ${ }^{18}$

In the current study we investigated the effects after 4 years of early versus delayed DMARD treatment on the radiological outcome of RA. We presumed that longlasting disease modification had only occurred if the rate of radiographic progression was less in the early treatment group than in the delayed treatment group in the years after the period of different treatment. In addition, the association of HLA class II genes with progression of joint damage was determined in both groups to investigate whether early treatment modifies the disease mechanism.

\section{PATIENTS AND METHODS}

\section{Patients}

In 1993 a special early arthritis clinic (EAC) was started at the Department of Rheumatology of the Leiden University Medical Centre, The Netherlands, the only centre for rheumatic disease patients in an area with 300000 inhabitants. General practitioners in this area were instructed to refer patients when arthritis was suspected. Patients could be seen at the EAC within 2 weeks. At the second visit, 2 weeks later, the diagnosis "definite rheumatoid arthritis" was made according to the 1987 American College of Rheumatology (ACR) criteria, ${ }^{20}$ and the diagnosis "probable rheumatoid arthritis" was made according to the 1958 ACR criteria, without the requirement of the 6 week observation period. Follow up visits were planned after 3 months, 6 months, and every year. The data of first and follow up visits were entered in the EAC database and consisted of history taking, physical diagnostic measurements, laboratory and radiographic parameters. For this study, we used the data of 4 years of follow up.

\section{Study design}

This was an observational study, in which two different treatment strategies were followed, during two subsequent time periods in a non-randomised design.

The delayed treatment group $(\mathrm{n}=109)$ group visited the EAC for the first time between January 1993 and December 1995, during which patients with RA were treated consistently according to the delayed or "pyramid" strategy, in which DMARDs are restricted to patients who are resistant to symptomatic treatment (non-steroidal anti-inflammatory drugs (NSAIDs)). After about 5 months (median 152 days), patients who still had active disease received the disease modifying drug chloroquine or Salazopyrin (sulfasalazine), prescribed in therapeutic dosage, which at that time were the preferred drugs for early RA in the Netherlands. Patients were considered to have active disease if they fulfilled at least three of the following criteria: morning stiffness longer than 30 minutes, more than five swollen joints, Ritchie score greater than 15, or erythrocyte sedimentation rate greater than $28 \mathrm{~mm} / \mathrm{lst} \mathrm{h}$. If disease control was insufficient according to the clinical judgment of the rheumatologist, or in cases of intolerance, the rheumatologist was free to choose another DMARD. Patients with mild disease were not treated with disease modifying drugs.

The early treatment group $(\mathrm{n}=97)$ visited the clinic between January 1996 and December 1998, after the decision had been made to treat all patients with probable or definite RA as soon as possible with a DMARD in addition to NSAIDs 2 weeks after referral. Only those patients who were diagnosed with probable or definite RA within 2 weeks of their first visit were included in the study. DMARDs were prescribed according to the same protocol as described above, except that patients with mild disease were also treated with disease modifying drugs.

During the 4 year follow up, both patient groups were treated with DMARDs according to the judgment of the rheumatologist, varying from no drugs to combination therapy with or without prednisolone.

For this study we compared the treatment strategies (early $v$ delayed) in relation to (progression of) radiographic joint damage, HLA class II association, and rheumatoid factor (RF) association.

\section{Outcome measurements}

Radiological progression

Radiographs of the hands and feet were obtained at study entry, at 6 months, and at 1, 2, 3, and 4 years. Radiographic damage was scored according to the modified Sharp/van der Heijde method ${ }^{21}$ in two sessions by one experienced rheumatologist. During the first session radiographs of 0 , 6 months, 1 and 2 years were randomly scored. The intraclass correlation coefficient for the assessor's scoring was 0.91 , as measured in 52 patients. Radiographs of the third and fourth year were scored during the second session, with an intraclass correlation coefficient for the assessor's scoring of 0.98 , as measured in 42 patients. The rheumatologist was unaware of the clinical data and the study questions.

\section{Laboratory examinations}

The presence of IgM RF was determined at study entry and was measured by enzyme linked immunosorbent assay. ${ }^{22}$ IgM RF titres $\geqslant 5$ units were considered positive. The association between HLA class II alleles and joint damage was determined by looking at the presence of the shared epitope (SE) in relation to joint damage. According to the SE model, certain common amino acid sequences (so called shared epitopes) influence the interaction with the T cell receptor in RA associated HLA-DRBl alleles. ${ }^{23}$ DNA isolation, DRBl typing and subtyping, and DQB1 typing were performed as described previously. ${ }^{24} 25$

The SE+ DRB1 alleles are ${ }^{*} 0101,{ }^{*} 0102,{ }^{*} 0401,{ }^{*} 0404$, *0405, *0408, and *1001.

\section{Completers-only analysis}

To avoid bias in the results by patients who were lost to follow up, we performed a completers-only analysis. In this analysis we included only those patients for whom a 3 to 4 year follow up (radiographs) was available.

\section{Statistical analysis}

For each patient separately simple linear regression was used to fit the course of the radiological progression. In both groups, the median slope was calculated. Progression rates were calculated, assuming that radiological damage progresses at a constant rate. ${ }^{26}{ }^{27}$ Differences between the patient characteristics and slopes of the (sub)groups of interest were tested with the Mann-Whitney $U$ test and Wilcoxon signed ranks test. All tests were two tailed and $p$ values $\leqslant 0.05$ were considered significant.

To construct fig 1, the geometric mean of the Sharp scores was calculated. Because the median Sharp scores of the two groups were very skewed as a result of missing measurements at different times, they were log transformed after adding 0.5 to the Sharp score. The average log Sharp scores with 95\% confidence interval were estimated using a linear mixed model, with time, treatment group, and the interaction as fixed effects and the patient number as random effect. In this way account was taken of repeated Sharp measurements on one patient and missing measurements. The log means with confidence 


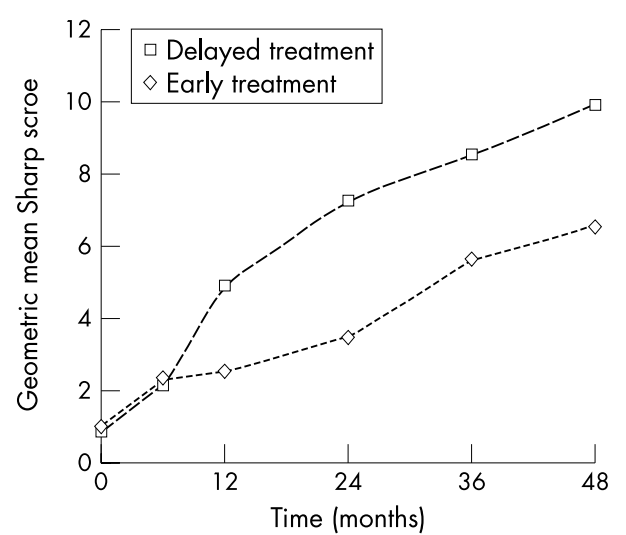

Figure 1 Geometric mean Sharp score (see "Patients and methods; Statistical analysis") of early (group 2) versus delayed treatment (group 1) strategy from study entry to 4 years. $95 \% \mathrm{Cl}$ for $\mathrm{t}=0$ in group 110.49 to 1.49 ), group 2 (0.58 to 1.70); for $t=6$ in group 1 (1.32 to 3.35$)$, in group 2 ( 1.45 to 3.61 ); for $t=12$ in group 1 (3.32 to 7.24$)$, in group 2 (1.62 to 3.81 ); for $t=24$ in group 1 (4.95 to 10.63 ), in group 2 (2.28 to 5.22 ); for $t=36$ in group 1 (5.88 to 12.34), in group 2 (3.79 to 8.26 ); for $\mathrm{t}=48$ in group 1 (6.77 to 14.43$)$, in group 2 (4.40 to 9.68$)$.

interval were then transformed back to the original scale, yielding estimates of the geometric mean of the Sharp score.

\section{RESULTS}

\section{Patient characteristics}

Between 1993 and 1995109 consecutive patients with RA (definite and probable) were included in the delayed treatment group. Subsequently, 97 consecutive patients were included in the early treatment group from 1996 to 1998.

Follow up of 3 to 4 years was available for 153 patients. Follow up of 53 patients $(25 \%)$ was lost. Reasons for incomplete follow up of these 53 patients were diverse: 43 patients were definitely lost to follow up and of the remaining 10, radiographs were lost or not taken at the right time. In the delayed treatment group nine patients had died, six were in remission, four refused follow up, two had moved to different cities, five were lost because of unknown cause, and two because of concomitant illnesses. In the early treatment group two patients had died, three were in remission, three refused follow up, one had moved to another city, four were lost because of unknown cause, and two because of concomitant illnesses. Patients who were lost to follow up differed from the completers-only group in age (median age in the lost group was 64 years compared with 55 in the completer group; $\mathrm{p}=0.02$ ) and presence of RF (percentage RF+ patients was 36\% in the lost group compared with $63 \%$ in the completer group; $\mathrm{p}=0.0001)$.

Patients in the completers-only group (total $n=153$ ) had similar age, sex, duration of symptoms, presence of RF, and disease activity at diagnosis as the original group, as shown in table 1 and in the article by Lard et al. ${ }^{9}$ The median lag time for the institution of DMARD treatment after diagnosis was considerably longer in the delayed treatment group (about 5 months) than in the early treatment group (2 weeks), reflecting the different treatment strategies. The erythrocyte sedimentation rate (ESR) was significantly lower in the early treatment group at all times, but measured as a percentage the ESR decreased equally in both groups. At all times, the percentage of the groups who received DMARD treatment and the cumulative number of DMARDs used was higher in the early treatment group.

\section{Outcome}

Table 2 shows that at 1 year of follow up, a significant difference was found between the median radiological progression of 5.0 points Sharp score per year in the delayed treatment group and the 1.0 point per year in the early treatment group $(p=0.005)$. At 2 years, this difference in progression rate was still substantial with 4.1 points per year in the delayed treatment group versus 1.0 point per year in the early treatment group $(\mathrm{p}=0.001)$.

When the progression rate was determined from study entry to 4 years, the difference between the two treatment strategies was still in favour of the early treatment group with 2.5 points per year in the delayed treatment group versus 1.3 points per year in the early treatment group, although less pronounced than during the first 2 years $(\mathrm{p}=0.032)$.

Because we presumed that longlasting disease modification had only occurred if the rate of radiographic progression was less in the early treatment group than in the delayed treatment group in the years after the period of different treatment, the progression rates from 1 to 4 years and from 2 to 4 years were also calculated. During both intervals, the progression scores were not significantly different $(p=0.52$ and 0.82 , respectively).

Figure 1 shows the differences in the progression of Sharp/ van der Heijde scores between the two treatment groups over an observation period of 4 years. This figure shows a higher rate of radiographic progression during the first and second year than during the third and fourth year. During the last 23 years, radiological joint damage progressed at an equal rate in both groups.

\section{Subgroup analysis}

Comparable results were found in the subgroup of patients who fulfilled the ACR classification criteria at the first visit as in the total group (table 3). For those patients who fulfilled the criteria of probable RA, a beneficial effect of early treatment was seen at 2 years, but not at 4 years. For the intervals $0-4,1-4$, and 2-4 years, similar progression scores of approximately one point Sharp score per year were seen in both the delayed and the early treatment subgroup of patients with probable RA. Among patients with a Sharp score of 0 at diagnosis, no significant difference in the progression of radiological damage between the delayed and early treatment groups was seen. Among those with a Sharp score $>0$ at diagnosis, substantially less progression was observed in the early treatment group at all time points ( 1 year; $p=0.008$ (data not shown), 2 years; $p=0.001$, and 4 years $\mathrm{p}=0.009)$. For these Sharp subgroups, no differences between the intervals of 1 to 4 years and 2 to 4 years were seen.

Table 4 shows the significant differences in the progression of joint damage at both times in the delayed treatment group in patients who were SE+ or RF+ compared with patients who were $\mathrm{SE}-$ or $\mathrm{RF}-$. In the early treatment group the association between radiographic progression and SE+ patients was also seen at 4 years $(p=0.041)$, in contrast with the findings at 2 years. ${ }^{24} 28$ The difference in Sharp score between RF+ and RF- patients was significant at both 2 and 4 years.

\section{DISCUSSION}

In this study we tested whether early treatment with DMARDs would prevent acquirement of detrimental disease characteristics as measured by the rate of joint destruction. Except for the first year, the rate of joint destruction was found to be equal in both the delayed and the early treatment group. This higher rate of joint destruction in the delayed treatment group during the first year accounts for the 
Table 1 Characteristics of the delayed treatment group and the early treatment group

\begin{tabular}{|c|c|c|c|}
\hline Characteristic & $\begin{array}{l}\text { Delayed group } \\
(n=78)\end{array}$ & $\begin{array}{l}\text { Early group } \\
(\mathrm{n}=75)\end{array}$ & $\mathrm{p}$ Value \\
\hline Age (years) & $57(44-65)$ & $52(42-68)$ & \\
\hline Female sex & $57(73)$ & $51(68)$ & \\
\hline Duration of symptoms at first visit (days) & $171(93-305)$ & $128(62-246)$ & \\
\hline Definite rheumatoid arthritis & $52(67)$ & $51(68)$ & \\
\hline Probable rheumatoid arthritis & $26(33)$ & $24(32)$ & \\
\hline Rheumatoid factor positive & $48(62)$ & $44(59)$ & \\
\hline Active disease ${ }^{*}$ & $33(42)$ & $34(45)$ & \\
\hline $\begin{array}{l}\text { Time to start disease modifying drug treatment } \\
\text { from first visit (days) }\end{array}$ & $152(55-293)$ & $15(14-21)$ & $\ddagger$ \\
\hline \\
\hline At baseline & $36(100)$ & $29(100)$ & $\ddagger$ \\
\hline 6 Monthst & $36(100)$ & $20(67)$ & \\
\hline 1 Year & $32(89)$ & $13(45)$ & \\
\hline 2 Years & $27(75)$ & $18(62)$ & \\
\hline 3 Years & $24(67)$ & $17(59)$ & \\
\hline 4 Years & $24(67)$ & $17(59)$ & \\
\hline \multicolumn{4}{|l|}{ DMARD use (patients) } \\
\hline 2 Weeks & $0(0)$ & $75(100)$ & $\ddagger$ \\
\hline 1 Year & $42(54)$ & $72(96)$ & $\ddagger$ \\
\hline 2 Years & $41(53)$ & 70 (93) & $\ddagger$ \\
\hline 3 Years & $48(62)$ & $67(89)$ & $\ddagger$ \\
\hline 4 Years & $49(63)$ & $65(87)$ & $\ddagger$ \\
\hline Cumulative number of DMARDs per person in & $1(0-3)$ & $2(1-3)$ & $\ddagger$ \\
\hline $\begin{array}{l}4 \text { years } \\
\text { Sharp score at baseline }\end{array}$ & $0(0-2)$ & $0(0-3)$ & \\
\hline \multicolumn{4}{|c|}{$\begin{array}{l}\text { Results are shown as number (\%) or median (interquartilerange) } \\
\text { "Defined as at least three of the following criteria: morning stiffness longer than } 30 \text { minutes, more than five swollen } \\
\text { joints, Ritchie score greater than } 15 \text {, or ESR greater than } 28 \mathrm{~mm} / 1 \mathrm{st} h \text {; }+ \text { percentage in relation to baseline ESR; } \\
\neq \mathrm{f}<0.05 \text { in the delayed treatment group versus those in the early treatment group. }\end{array}$} \\
\hline
\end{tabular}

beneficial effect of early DMARD treatment at 4 years in this radiographic analysis. However, once more than $50 \%$ of both groups received DMARD treatment, differences in the rate of joint destruction were no longer seen between the two groups. In this specific study, no support for the "window of opportunity" hypothesis was seen. Thus, the fact that early treatment is associated with less inflammation and cumulative damage, does not imply a "window of opportunity" for the long term effect.

Subgroup analysis of the group with probable RA and the radiographically undamaged group showed no long term favourable effects of early treatment. The observation that the association of HLA class II alleles and the rate of joint destruction is abolished by early treatment, was not seen after 4 years. This also indicates that longlasting modification of disease mechanisms was not achieved. The loss of association between HLA class II alleles and radiographic joint damage at 2 years was reported in both this cohort and the combination therapy group of the COBRA study, which

Table 2 Median slopes reflecting radiological progression per year (interquartile range) among patients with recent onset RA treated according to different strategies (Leiden EAC study)

\begin{tabular}{llll}
\hline $\begin{array}{l}\text { Slope at } \\
\text { year(s) }\end{array}$ & $\begin{array}{l}\text { Delayed treatment } \\
\text { group }(\mathbf{n}=\mathbf{7 8})\end{array}$ & $\begin{array}{l}\text { Early treatment } \\
\text { group }(\mathbf{n}=75)\end{array}$ & $\mathbf{p}$ Value \\
\hline $0-1$ & $5.0(0,15.0)$ & $1.0(0,5.0)$ & 0.005 \\
$0-2$ & $4.1(0.5,12.6)$ & $1.0(0,5.3)$ & 0.001 \\
$0-4$ & $2.5(0.5,7.7)$ & $1.3(0,4.4)$ & 0.032 \\
$1-4$ & $0.9(0,7.0)$ & $0.7(0,4.2)$ & 0.52 \\
$2-4$ & $1.0(0,6.5)$ & $1.0(0,5.3)$ & 0.82 \\
\hline
\end{tabular}

Slope 0-1 year: based upon radiographs at study entry, 6 months, and 1 year; slope 0-2 years: based upon radiographs at study entry, 6 months, 1, and 2 years; slope $0-4$ years: based upon radiographs at study entry, 6 months, 1, 2, 3, and 4 years; slope 1-4 years: based upon radiographs at 1, 2, 3, and 4 years; slope 2-4 years: based upon radiographs at 2,3 , and 4 years. compared initial intensive combination treatment, including high dose corticosteroids, with sulfasalazine monotherapy. ${ }^{18}$ To explain this finding it was suggested that early and aggressive treatment prevented the involvement of autoreactive $\mathrm{T}$ cells in the immune response. Because our 4 year data do not confirm a longlasting effect of early treatment, this theory is either incorrect or the effect of the currently investigated early treatment is not long lasting. Nowadays, RA is treated more aggressively than in the period during which this study was performed. So far, it is unknown whether the results of this study apply to present day treatment.

It needs to be discussed whether specific characteristics of our study may lead to limited generalisability. The present study is an observational cohort study, in which the rheumatologists were, apart from the delayed versus early treatment strategy, free to choose DMARDs. This led to a similar type of DMARD treatment in both cohorts, although not all patients were treated. The advantage of this approach is that the data reflect common practice, but the disadvantage is that subgroup analysis is no longer possible owing to confounding by indication. However, this line of reasoning does not inhibit subgroup analysis of prognostic factors not requested by the rheumatologist, such as genetic risk factors. As a result, the subgroup analysis of SE is valid, but the subgroup analyses of patients who fulfilled the ACR criteria for definite or probable RA as well as the Sharp subgroups may be affected by this phenomenon. Other disadvantages of this study are the $25 \%$ loss to follow up and the artefacts that may arise from secular changes, such as differences in preferential treatment in different time periods. This is reflected in the slightly higher percentage of DMARD treated patients in the early treatment group. However, this artefact would have skewed the results towards a better radiological outcome in the early treatment group at all time points, thereby supporting the hypothesis that early treatment with DMARDs would have a longlasting effect on the joint damaging properties of RA. However, no 
Table 3 Modified Sharp progression rate (points per year) after 2 years, 4 years, and from 1 to 4 years in the delayed and early treatment groups, stratified by diagnosis of definite versus probable RA and by Sharp score at baseline (Leiden EAC study)

\begin{tabular}{|c|c|c|c|c|c|c|c|c|}
\hline \multirow[b]{2}{*}{ Subgroup } & \multicolumn{4}{|c|}{ Delayed treatment group } & \multicolumn{4}{|c|}{ Early treatment group } \\
\hline & $\begin{array}{l}\text { No of } \\
\text { patients }\end{array}$ & $\begin{array}{l}\text { Change } \\
0-2 \text { years }\end{array}$ & $\begin{array}{l}\text { Change } \\
0-4 \text { years }\end{array}$ & $\begin{array}{l}\text { Change } \\
1-4 \text { years }\end{array}$ & $\begin{array}{l}\text { No of } \\
\text { patients }\end{array}$ & $\begin{array}{l}\text { Change } \\
0-2 \text { years }\end{array}$ & $\begin{array}{l}\text { Change } \\
0-4 \text { years }\end{array}$ & $\begin{array}{l}\text { Change } \\
1-4 \text { years }\end{array}$ \\
\hline \multicolumn{9}{|c|}{ Diagnosis at baseline } \\
\hline Definite RA & 52 & $6.1(1.7,16.8)^{*}$ & $3.1(0.8,7.2)^{*}$ & $1.0(0,8.4)$ & 51 & $1.6(0,10.8)$ & $1.8(0.2,4.4)$ & $0.6(0,3.4)$ \\
\hline Probable RA & 25 & $1.9(0,2.4)^{*}$ & $0.8(0.5,4.8)$ & $0.7(0,3.6)$ & 24 & $0.0(0,2.4)$ & $0.6(0,4.9)$ & $0.8(0,7.3)$ \\
\hline \multicolumn{9}{|c|}{ Sharp score at baseline } \\
\hline 0 & 37 & $1.6(0,6.5)$ & $1.0(0,6.8)$ & $0.8(0,6.1)$ & 31 & $1.0(0,4.7)$ & $1.8(0.4,5.6)$ & $2.0(0,6.0)$ \\
\hline$>0$ & 36 & $7.2(3.0,15.0)^{*}$ & $3.0(1.4,6)^{*}$ & $0.8(0,3.4)$ & 39 & $1.0(0,7.7)$ & $1.1(0,3.4)$ & $0.5(0,3.1)$ \\
\hline
\end{tabular}

Values are the median (25th-75th centile).

${ }^{*} \mathrm{p}<0.05$ in the delayed treatment group versus those in the early treatment group.

Table 4 Influence of HLA class II antigens and rheumatoid factor on the joint damage progression score per year among patients with recent onset RA treated according to different strategies (Leiden EAC study)

\begin{tabular}{|c|c|c|c|c|c|c|}
\hline & \multicolumn{3}{|c|}{ Delayed treatment group } & \multicolumn{3}{|c|}{ Early treatment group } \\
\hline & No of patients & Change $0-2$ years & Change $0-4$ years & No of patients & Change $0-2$ years & Change $0-4$ years \\
\hline \multicolumn{7}{|c|}{ Shared epitope } \\
\hline Positive & 52 & $7.0(2.2,17.0)^{*}$ & $3.1(0.8,7.7)^{*}$ & 45 & $1.0(0,7.4) \dagger$ & $2.2(0.3,5.6) \ddagger$ \\
\hline Negative & 24 & $0.5(0,5.8)$ & $0.8(0,3.4)$ & 26 & $0.9(0,3.0)$ & $0.5(0,1.9)$ \\
\hline \multicolumn{7}{|c|}{ Rheumatoid factor } \\
\hline Positive & 48 & $6.7(2.5,18.2)^{*}$ & $3.4(1.4,9.4)^{*}$ & 44 & $2.0(0,13.2)^{*}$ & $2.5(0.8,5.8)^{*}$ \\
\hline Negative & 30 & $1.7(0,7.6)$ & $0.7(0,2.8)$ & 30 & $0.5(0,2.0)$ & $0.3(0,1.3)$ \\
\hline
\end{tabular}

Values are the median (25th-75th centile).

${ }^{*} p<0.05$ versus those in the same treatment group who were negative for the feature; $† p$ not significant versus those in the same treatment group who were negative for the feature; $\ddagger p=0.041$ versus those in the same treatment group who were negative for the feature.

difference in the rate of joint damage from 1 to 4 years was observed.

The baseline characteristics of the patients in this study are roughly comparable with those of other cohort studies in early rheumatoid disease, which have supported the short term "window of opportunity" hypothesis. ${ }^{81011}$ However, these trials have follow up duration of maximum 2 years, whereas the results of our study indicate that longer follow up is necessary. As mentioned earlier, long term follow up $(>2$ years) of early treatment strategies in order to confirm or reject this "window of opportunity" hypothesis is scarce. The studies that have been carried out to answer this question, both reported the opposite result. Our findings are in accordance with a 3 year prospective study that compared DMARD treatment in very early RA (symptoms $<4$ months; $\mathrm{n}=27$ )) with that in early RA (symptoms 4-24 months; $\mathrm{n}=122) .{ }^{29}$ The parallel progression rates in that study were addressed to a more aggressive form of RA in the very early treatment group, as pointed out by a significant difference in the duration of symptoms between the two groups (3.1 months in the very early group versus 9.2 months in the early group). However, in our present study, no indication for differences in disease severity was observed.

The question that arises from our results is whether the "window of opportunity" hypothesis is incorrect or whether the timing and type of early treatment, as in the current study, are not enough to prevent acquirement of detrimental disease characteristics as measured by the rate of joint destruction.

Several studies show that combination therapy of several DMARDs or the combination with corticosteroids is more effective in suppressing disease activity and radiological progression, at least during the first 2 years. ${ }^{19} 3031$ The recently published results of the 5 year follow up of the COBRA study show that the beneficial effect of combination therapy is sustained with regard to suppression of radiological progression, even after 5 years. ${ }^{32}$ The modified Sharp/ van der Heijde progression rate was 5.6 points a year in the 74 patients originally randomised to the combination therapy group, compared with 8.6 in the 74 patients randomised to the Salazopyrin (sulfasalazine) group. The higher progression rates in this trial can be explained by the inclusion criteria of the COBRA study, which allowed only patients with more severe RA to be included. The progression rate of 5.6 points a year in a combination therapy treated group is very high, given the median progression of a couple of points a year in a general group of patients treated with DMARDs in a recent review on radiological progression in a large number of trials. ${ }^{33}$ The progression of joint destruction in a large number of DMARD treated patients in our cohort is comparable to the progression in DMARD treated patients as reviewed in this article.

In conclusion, the current data confirm that the beneficial effect of early DMARD treatment in reducing joint damage is still present at 4 years. However, after 1 year, when more than $50 \%$ in both patient groups received DMARD treatment, no differences in the rate of joint damage could be observed. Thus, no prevention of detrimental characteristics during a "window of opportunity" was seen from early DMARD treatment after 4 years.

\section{ACKNOWLEDGEMENTS}

We thank Professor A Cats for radiographic scoring.

This study was supported by the Dutch Arthritis Foundation.

\section{Authors' affiliations}

J van Aken, L R Lard, S le Cessie, F C Breedveld, T W J Huizinga, Leiden University Medical Centre, Leiden, The Netherlands

J M W Hazes, Erasmus Medical Centre, Rotterdam, The Netherlands 


\section{REFERENCES}

1 Pincus T, Callahan LF. What is the natural history of rheumatoid arthritis? Rheum Dis Clin North Am 1993;19:123-51.

2 Scott DL, Symmons DP, Coulton BL, Popert AJ. Long-term outcome of treating rheumatoid arthritis: results after 20 years. Lancet 1987;1:1108-11.

3 van Zeben D, Hazes JM, Zwinderman AH, Vandenbroucke JP, Breedveld FC. The severity of rheumatoid arthritis: a 6-year followup study of younger women with symptoms of recent onset. J Rheumatol 1994;21:1620-5.

4 Pincus T. Rheumatoid arthritis: disappointing long-term outcomes despite successful short-term clinical trials. J Clin Epidemiol 1988:41:1037-41.

5 Furst DE. Rational use of disease-modifying antirheumatic drugs. Drugs 1990;39: 19-37.

6 Cash JM, Klippel JH. Second-line drug therapy for rheumatoid arthritis. N Engl J Med 1994;330:1368-75.

7 Huizinga TW, Machold KP, Breedveld FC, Lipsky PE, Smolen JS. Criteria for early rheumatoid arthritis: from Bayes' law revisited to new thoughts on pathogenesis. Arthritis Rheum 2002;46:1552-9.

8 Hannonen P, Mottonen T, Hakola M, Oka M. Sulfasalazine in early rheumatoid arthritis. A 48-week double-blind, prospective, placebo-controlled study. Arthritis Rheum 1993;36:1501-9.

9 Lard LR, Visser H, Speyer I, vander Horst-Bruinsma IE, Zwinderman AH, Breedveld FC, et al. Early versus delayed treatment in patients with recentonset rheumatoid arthritis: comparison of two cohorts who received different treatment strategies. Am J Med 2001;111:446-51.

10 van der Heide A, Jacobs JW, Bijlsma JW, Heurkens AH, Booma-Frankfort C, van der Veen MJ, et al. The effectiveness of early treatment with "second-line" antirheumatic drugs. A randomized, controlled trial. Ann Intern Med 1996; 124:699-707

11 Borg G, Allander E, Lund B, Berg E, Brodin U, Pettersson H, et al. Auranofin improves outcome in early rheumatoid arthritis. Results from a 2 -year, double blind, placebo controlled study. J Rheumatol 1988;15:1747-54.

12 Egsmose C, Lund B, Borg G, Pettersson H, Berg E, Brodin U, et al. Patients with rheumatoid arthritis benefit from early 2 nd line therapy: 5 year followup of a prospective double blind placebo controlled study. J Rheumatol 1995;22:2208-13.

13 Mottonen T, Paimela L, Ahonen J, Helve T, Hannonen P, Leirisalo-Repo M. Outcome in patients with early rheumatoid arthritis treated according to the "sawtooth" strategy. Arthritis Rheum 1996;39:996-1005.

14 van Zeben D, Hazes JM, Zwinderman AH, Cats A, Schreuder GM, D'Amaro J, et al. Association of HLA-DR4 with a more progressive disease course in patients with rheumatoid arthritis. Results of a followup study. Arthritis Rheum 1991;34:822-30.

15 Emery P, Salmon M, Bradley H, Wordsworth P, Tunn E, Bacon PA, et al. Genetically determined factors as predictors of radiological change in patients with early symmetrical arthritis. BMJ 1992;305:1387-9.

16 van der Heijde DM, van Riel PL, van Leeuwen MA, van't Hof MA, van Rijswijk MH, van de Putte LB. Prognostic factors for radiographic damage and physical disability in early rheumatoid arthritis. A prospective follow-up study physical disability in early rheumatoid arthritis. A pros
of 147 patients. Br J Rheumatol 1992;31:519-25.

17 Weyand CM, Hicok KC, Conn DL, Goronzy JJ. The influence of HLA-DRB 1 genes on disease severity in rheumatoid arthritis. Ann Intern Med 1992;117:801-6.
18 Lard LR, Boers M, Verhoeven A, Vos K, Visser H, Hazes JM, et al. Early and aggressive treatment of rheumatoid arthritis patients affects the association of HLA class II antigens with progression of joint damage. Arthritis Rheum 2002;46:899-905.

19 Boers M, Verhoeven AC, Markusse HM, van de Laar MA, Westhovens R, van Denderen JC, et al. Randomised comparison of combined step-down prednisolone, methotrexate and sulphasalazine with sulphasalazine alone in early rheumatoid arthritis. Lancet 1997;350:309-18.

20 Arnett FC, Edworthy SM, Bloch DA, McShane DJ, Fries JF, Cooper NS, et al The American Rheumatism Association 1987 revised criteria for the classification of rheumatoid arthritis. Arthritis Rheum 1988;31:315-24.

21 van der Heijde DM. Plain X-rays in rheumatoid arthritis: overview of scoring methods, their reliability and applicability. Baillieres Clin Rheumatol 1996; 10:435-53.

22 Visser H, Gelinck LB, Kampfraath AH, Breedveld FC, Hazes JM. Diagnostic and prognostic characteristics of the enzyme linked immunosorbent rheumatoid factor assays in rheumatoid arthritis. Ann Rheum Dis 1996:55:157-61.

23 O'Dell JR, Nepom BS, Haire C, Gersuk VH, Gaur L, Moore GF, et al. HLADRB 1 typing in rheumatoid arthritis: predicting response to specific treatments. Ann Rheum Dis 1998;57:209-13.

24 van der Horst-Bruinsma I, Visser $\mathrm{H}$, Hazes JM, Breedveld FC, Verduyn W, Schreuder GM, et al. HLA-DQ-associated predisposition to and dominant HLA-DR-associated protection against rheumatoid arthritis. Hum Immunol 1999:60:152-8.

25 Winchester R, Dwyer E, Rose S. The genetic basis of rheumatoid arthritis. The shared epitope hypothesis. Rheum Dis Clin North Am 1992;18:761-83.

26 Hulsmans HM, Jacobs JW, van der Heijde DM, Albada-Kuipers GA, Schenk Y, Bijlsma JW. The course of radiologic damage during the first six years of rheumatoid arthritis. Arthritis Rheum 2000;43:1927-40.

27 Wolfe F, Sharp JT. Radiographic outcome of recent-onset rheumatoid arthritis: a 19-year study of radiographic progression. Arthritis Rheum 1998;41:1571-82.

28 Zanelli E, Breedveld FC, De Vries RR. HLA class II association with rheumatoid arthritis: facts and interpretations. Hum Immunol 2000;61:1254-61.

29 Peltomaa R, Paimela L, Helve T, Leirisalo-Repo M. Effect of treatment on the outcome of very early rheumatoid arthritis. Scand J Rheumatol 2001;30:143-8.

30 Calguneri M, Pay S, Caliskaner Z, Apras S, Kiraz S, Ertenli I, et al. Combination therapy versus monotherapy for the treatment of patients with rheumatoid arthritis. Clin Exp Rheumatol 1999;17:699-704.

31 Mottonen T, Hannonen P, Leirisalo-Repo M, Nissila M, Kautiainen H, Korpela $M$, et al. Comparison of combination therapy with single-drug therapy in early rheumatoid arthritis: a randomised trial. FIN-RACo trial group. Lancet 1999;353:1568-73.

32 Landewe RB, Boers M, Verhoeven AC, Westhovens R, van de Laar MA Markusse $\mathrm{HM}$, et al. COBRA combination therapy in patients with early rheumatoid arthritis: long-term structural benefits of a brief intervention. Arthritis Rheum 2002;46:347-56.

33 Strand V, Sharp JT. Radiographic data from recent randomized controlled trials in rheumatoid arthritis: what have we learned? Arthritis Rheum 2003;48:21-34 